\title{
Sport Fan Team Identification Formation in Mid-Level Professional Sport
}

\author{
P. BRIAN GREENWOOD, MICHAEL A. KANTERS \& \\ JONATHAN M. CASPER
}

\begin{abstract}
Team identification, the degree to which an individual feels psychologically linked to a team, has been a focal point in studies of sport fans and sport spectatorship (e.g. Fink et al., 2002; Jones, 1997; Wann \& Branscombe, 1993; Wann \& Dolan, 1994; Wann \& Schrader, 1997). Although the development of team identification has been examined extensively in established sport markets, the purpose of this study is to assess the relationship between sport fan team identification and motivations for initially becoming a fan of a new mid-level professional sport in a new market. A convenience sample of spectators $(N=351)$ at an American Arena Football League (AFL) game completed a survey designed to identify and measure this relationship. A simultaneous multiple regression analysis revealed significant and positive predictive value for team identification from the following reasons for becoming a fan: parents and/or family $(\beta=.125, p<.05)$, born and/or live in area $(\beta=.210, p<.001)$, players and/or coaches $(\beta=.411, p<.001)$, and tailgating and party atmosphere $(\beta=.123, p<.05)$. The results have practical marketing implications for mid-level professional sport franchises (i.e. Women's National Basketball Association, NFL-Europe, Major League Soccer) and highlight the need for additional research across the professional sport spectrum, as franchises in these leagues struggle for market share against competing sport and entertainment options.
\end{abstract}

\section{Introduction}

As the face of professional sport continues to evolve around the globe, the need for research on the consumers of sport products and services has never been more important. Like any product in the marketplace, a clear understanding of consumer behavior, attitudes, and desires provides valuable 
information for determining how best to place, package, price, and promote products. The principal 'product' for professional sport is the live sporting event. Most professional sport teams reside in established markets with set fan bases that tend to either remain loyal or 'ebb and flow' with team success. However, professional sport at all levels is a growing enterprise with new sports, leagues, and teams forming in cities around the world. The mid-level professional sport franchises (i.e. Women's National Basketball Association, NFL-Europe, Major League Soccer) have a high potential growth quotient, as these leagues struggle to reach the level of fan support and public profile necessary to be deemed elite or high-level professional sport (i.e. English Premiere League, National Football League, National Basketball Association). Therefore, the need for research on the fans of mid-level professional sport franchises in new markets provides an opportunity to further examine motivations for identifying with a particular team.

Research on factors that contribute to the development of sport spectatorship has been widely documented over the last decade (e.g. James \& Ross, 2004; Pease \& Zhang, 1996; Trail et al., 2003; Wann et al., 2001). One factor that has emerged in the literature is the importance of team identification. Team identification, or the degree to which an individual feels psychologically linked to a team, has been a major focal point in recent studies of sport fans and their sport spectatorship behaviors (e.g. Fink et al., 2002; Jones, 1997; Wann \& Branscombe, 1993; Wann \& Dolan, 1994; Wann \& Schrader, 1997). A review of the sport fan team identification literature presents strong evidence of positive associations with many sport fan behaviors. Highly identified fans have been found to attend more games (Pease \& Zhang, 1996; Wakefield, 1995; Wann \& Branscombe, 1993; Wann et al., 1999), spend more money and time in the process of watching their team play (Wann \& Branscombe, 1993; Wann et al., 1999), are more optimistic about the teams' future success (Wann \& Branscombe, 1993), and view attendance at games as a more enjoyable experience (Madrigal, 1995; Wann \& Schrader, 1997). Further, research has shown that persons who strongly identify with a team tended to report more involvement with the team, display a more ego-enhancing pattern of attribution for the team's successes, have more positive expectations concerning future team performances, exhibit greater willingness to invest larger amounts of time and money watching the team play; and be more likely to believe that other fans belonging to their identified team possess special qualities (Wann \& Branscombe, 1993). Sport fans with high team identification levels are clearly the target consumers for spectator sport teams.

Wann et al. (2001) discovered that highly identified fans were more likely to be intrinsically motivated to originally follow a team, while Fink et al. (2002) found vicarious team achievement to be the greatest motivator for team identification. Specifically, Wann et al. (1996) found that parental and family influence, talent level and personality of players, peer influence/ geographic influence (tied), and success of the team were the five most prevalent reasons for initial identification with a team. The same study found that the prevailing reason for continued identification with a team was 
success quantified by won/loss record (Wann et al., 1996). In contrast, Jones (1997) argued that geographical reasons were the most dominant reason for continuing to support a team. Both studies have limitations that could easily have skewed the data in one way or another. Wann et al., for example, sampled college students who were more likely to be displaced from the location of their favorite team. Jones sampled English soccer fans who were obviously more highly localized than college students. Branscombe and Wann (1991) noted that sources of sport fan identification vary between local and displaced fans.

Although there appears to be relative agreement in the literature on certain sport fan team identification correlates (e.g. sport knowledge, spectator behavior, purchasing patterns), existing research has not clearly examined the process of team identification in new markets or mid-level professional sport contexts. Although all professional sport franchises are interested in developing highly identified sport fans, new sport franchises must achieve this goal without an existing fan base. Further, mid-level professional sport franchises must compete with a wide range of sport and entertainment options, and development of their fan base is potentially a unique endeavor.

The purpose of the current study was to examine sport fan team identification formation in the initial stages of a mid-level professional sport franchise's development. By examining sport fan team identification and popular correlates identified in previous empirical studies in the context of a new mid-level professional sport franchise, this study seeks to validate predictive factors for developing sport fans with a new product in a new market.

\section{Method}

The American Arena Football League (AFL) was selected as an appropriate mid-level professional sport league for examining team identification formation. Arena football is a fast-paced, high-scoring version of American football with a shortened field of play and reduced numbers of players on the field at one time. The AFL, established in 1987 with four initial teams, has grown in both teams and popularity over the last two decades, to its current size of 17 teams in 2006 (Arena Football Team History, 2006). Despite some volatility in terms of relocation and disbandment, the league has grown substantially in popularity and even includes a minor league, Arena Football 2 (af2) in 24 smaller markets around the United States (Arena Football Team History, 2006). Many of the AFL franchises were established in markets with an existing professional American football spectator base (i.e. New York, Los Angeles, Dallas), and the Carolina Cobras' franchise in Raleigh, North Carolina (NC) was initially tabbed to fit this mold with the National Football League's Carolina Panthers located only two hours away in Charlotte, NC. Building on game similarities to American football and the idea of 'capturing' the fan desiring to stay involved with American football, the AFL configured its season to fit into the void left by the NFL's off-season 
(February-August). The AFL schedule has varied over the years within that NFL off-season time frame with games currently being played from late January to early July (Arena Football Team History, 2006).

From a sport fan development perspective, midlevel professional sports like the AFL may build upon a strong base of fans for their sport (in this case football) but also have the added benefit of capitalizing on geographic proximity. For example, although sport fans may exhibit strong team identification for teams that play hundreds of miles away, they also may have a strong potential to develop team identification for a lower level team that plays in their community. This scenario exists in professional sports around the world. A sport fan living in Glasgow, Scotland, may exhibit high team identification characteristics for the Manchester United football team. This same sport fan may also display high team identification for the Queen's Park Football Club, an amateur club in the Scottish league. Although sport fans may exhibit high identification characteristics for both an elite and midlevel sports team, the factors that contribute to the development of team identification may be different.

The Carolina Cobras ${ }^{1}$, a second-year franchise for the AFL at the time of the study, was selected as the team for the current research. In Raleigh and North Carolina, the primary rooting interests for sport fans are collegiate sports with Atlantic Coast Conference (ACC) members North Carolina, Duke, and North Carolina State located within a 30 square mile radius. The area commonly referred to as 'Tobacco Road' is most known for collegiate basketball due to the prominence of the three area university teams. North Carolina in general is also well known as a 'hotbed' for stock-car auto racing, as NASCAR rose to prominence from its early roots in the state. The National Hockey League's Carolina Hurricanes shared a venue with the Cobras during this period, but the Hurricanes were eliminated from playoff contention at the time of the study. The Cobras competed with several sport options including: Minor League Baseball's Carolina. Mudcats and Durham Bulls, and NASCAR stock-car auto racing. However, during data collection in early May, the only high-profile sport competition was the minor league baseball teams.

\section{Participants}

A convenience sampling technique was employed as fans were presented with paper-and-pencil questionnaires at their seats for a regular season home game midway through the Cobras' second season in Raleigh. Questionnaires were distributed throughout the Cobras' venue prior to the start of the game. Research volunteers and Cobras' staff collected completed questionnaires prior to and throughout the first half of the game. Several public address announcements were made throughout the first half of the game, encouraging survey participants to complete and return the questionnaires. By halftime of the game, all completed surveys were collected. The $32 \%$ response rate (1,100 questionnaires distributed with 351 completed surveys) was adjusted to $44.5 \%$ to account for approximately 300 surveys being 
placed on empty seats. The Cobras' management did not provide researchers with a detailed layout of seats coinciding with tickets sold prior to the game, so surveys were randomly distributed in sections marked as the most popular sections.

\section{Measures}

A sport fan questionnaire was developed for this research with three sections relevant to this article including: Becoming a Fan, Team Identification, and You \& Your Household. The Becoming a Fan section asked subjects to rate their reasons for personally becoming a fan of the Cobras using a 5-point Likert-type scale $(1=$ not important, $5=$ very important). Six items (parents and/or family members, team's success, born and/or live in city or state, friends, players and/or coaches of the team, and closest geographical team) were included based on previous studies into initial factors of fan development (Fink et al., 2002; Jones, 1997; Wann et al., 1996; Wann et al., 2001). Two other variables were added at the request of the Vice President for Marketing and Promotions for the Cobras. These additional variables were: the 'Snake Charmers' (Cobras dance team) and the tailgating and party atmosphere. Tailgating is a term used to describe the act of socializing with other fans in the parking lot or surrounding area prior to the start of a scheduled contest. American football and tailgating are closely associated. James et al. (2001), in research on tailgating at American football games, concluded 'Tailgating provides managers of sporting events the opportunity to enhance the overall experience of attending a game' (p. 221). The inclusion of these two additional variables (dance team and tailgating/party atmosphere) is justified when considering entertainment and social elements as important aspects related to the professional sport experience.

The Team Identification section consisted of the seven items of the Sport Spectator Identification Scale (Wann \& Branscombe, 1993). The Sport Spectator Identification Scale (SSIS) has been utilized in numerous studies that verified the scale's reliability and sound psychometric properties (e.g. Gayton et al., 1998; Wann, 1996; Wann \& Branscombe, 1993; Wann et al., 2003). The SSIS combines seven items to form a single measure of identification. The seven items assess the individual's perceptions of being a fan of the particular team, the importance of winning, the degree to which the individual sees themselves as a fan of that team, the extent to which his/ her friends view themselves as a fan, how closely the individual follows the progress of the team, how often the fan displays or wears team memorabilia or team apparel, and to what degree the individual dislikes their respective team's principal rivals (Wann \& Branscombe, 1993). These responses were also based on a 5 -point Likert-type scale $(1=$ not at all descriptive of me, $5=$ very descriptive of me). Results from the current study yielded a Cronbach's alpha reliability coefficient of .86 for the SSIS scale. The You and Your Household section included socio-demographic items: gender, age, marital 
Table 1. Cross tabulation for ticket type and income category for study participants

\begin{tabular}{|c|c|c|c|c|c|c|c|}
\hline \multirow[b]{2}{*}{ Income } & & \multicolumn{6}{|c|}{ Ticket } \\
\hline & & Advance & Season & Mini-plan & Gate & Other & Total \\
\hline \multirow[t]{2}{*}{$<\$ 20 \mathrm{~K}$} & Count & 1 & 2 & 1 & 1 & 4 & 9 \\
\hline & $\%$ within Ticket & $3.7 \%$ & $1.1 \%$ & $6.3 \%$ & $20.0 \%$ & $5.8 \%$ & $3.0 \%$ \\
\hline \multirow[t]{2}{*}{$\$ 21 \mathrm{~K}-30 \mathrm{~K}$} & Count & 3 & 5 & 1 & & 3 & 12 \\
\hline & $\%$ within Ticket & $11.1 \%$ & $2.7 \%$ & $6.3 \%$ & & $4.3 \%$ & $4.0 \%$ \\
\hline \multirow[t]{2}{*}{$\$ 31 \mathrm{~K}-40 \mathrm{~K}$} & Count & 4 & 8 & 2 & 1 & 10 & 25 \\
\hline & $\%$ within Ticket & $14.8 \%$ & $4.3 \%$ & $12.5 \%$ & $20.0 \%$ & $14.5 \%$ & $8.3 \%$ \\
\hline \multirow[t]{2}{*}{$\$ 41 \mathrm{~K}-50 \mathrm{~K}$} & Count & 2 & 14 & 1 & & 3 & 20 \\
\hline & $\%$ within Ticket & $7.4 \%$ & $7.6 \%$ & $6.3 \%$ & & $4.3 \%$ & $6.6 \%$ \\
\hline \multirow[t]{2}{*}{$\$ 51 \mathrm{~K}-75 \mathrm{~K}$} & Count & 6 & 41 & 3 & 1 & 21 & 72 \\
\hline & $\%$ within Ticket & $22.2 \%$ & $22.2 \%$ & $18.8 \%$ & $20.0 \%$ & $30.4 \%$ & $23.8 \%$ \\
\hline \multirow[t]{2}{*}{$>\$ 75 \mathrm{~K}$} & Count & 11 & 115 & 8 & 2 & 28 & 164 \\
\hline & $\%$ within Ticket & $40.7 \%$ & $62.2 \%$ & $50.0 \%$ & $40.0 \%$ & $40.6 \%$ & $54.3 \%$ \\
\hline \multirow[t]{2}{*}{ Total } & Count & 27 & 185 & 16 & 5 & 69 & 302 \\
\hline & $\%$ within Ticket & $100.0 \%$ & $100.0 \%$ & $100.0 \%$ & $100.0 \%$ & $100.0 \%$ & $100.0 \%$ \\
\hline
\end{tabular}

$N=302$ (49 missing)

status, number of children in the household and the children's involvement with football, zip code, and household income.

\section{Results}

A majority of the survey participants were male $(76 \%)$, married $(62.5 \%)$, $26-50$ years old $(77.8 \%)$ and season ticket holders $(62.8 \%)$ with a household income of $\$ 50,000$ or more per year $(78.1 \%)$. For the 'describe your party' variable, participants often chose more than one descriptor for their party. Of the 394 affirmative descriptors marked for this variable, $91.4 \%$ considered their party as family and/or friends. With eight available home games, survey participants indicated that they had attended an average of 3.79 games $(S D=3.20)$ in the inaugural or previous season. This result reinforced the notion that season ticket holders were the dominant ticketing group of survey respondents. Table 1 presents the results of a cross tabulation comparison of study participants' income category against ticket type. Again, as expected, participants in higher income groups (i.e. greater than $\$ 50,000)$ typically purchase more tickets in all ticket categories.

A Pearson's correlation matrix was used to identify the inter-relationships between team identification and the reasons for initially becoming a fan. The results presented in Table 2 revealed significant correlations between team identification and the following variables: players and/or coaches of the team, party and tailgating atmosphere, born and/or live in Raleigh and/or North Carolina, parents and/or family members as fans, closest Arena Football League team, and team success. The dance team and friends as fans variables did not exhibit a significant correlation with team identification. 
Table 2. Pearson correlation matrix for team identification and reasons for becoming a fan

\begin{tabular}{|c|c|c|c|c|c|c|c|c|c|}
\hline & 1. & 2. & 3. & 4. & 5. & 6. & 7. & 8. & 9 . \\
\hline \multicolumn{10}{|l|}{ 1. Team ident. } \\
\hline 2. Family as fans & $.20 * *$ & & & & & & & & \\
\hline 3. Team success & $.14 * *$ & $.26 * *$ & & & & & & & \\
\hline 4. Born in area & $.24 * *$ & .03 & .04 & & & & & & \\
\hline 5. Dance team & .09 & .06 & $.21 * *$ & .01 & & & & & \\
\hline 6. Friends are fans & .07 & $.24 * *$ & $.26 * *$ & .07 & $.31 * *$ & & & & \\
\hline 7. Players/coaches & $.42 * *$ & $.22 *$ & $.4 * *$ & .05 & $.15 *$ & $.35 * *$ & & & \\
\hline 8. Party/tailgating & $.24 * *$ & $.17 * *$ & $.21 * *$ & $.10 * *$ & $.21 * *$ & $.35 * *$ & $.30 * *$ & & \\
\hline 9. Closest team & $.19 * *$ & .09 & $.16^{* *}$ & $.19 * *$ & -.00 & .08 & $.16^{* *}$ & $.16 * *$ & \\
\hline
\end{tabular}

$* p<.01, * p<<.001$

$N=351$

Multiple regression analysis was used to build a predictive model of sport fan team identification for this data set. A review of the previous correlation matrix revealed several bivariate relationships between sport fan team identification and potential predictor variables. The correlation matrix and a review of relevant literature on the initial reasons for becoming a sport fan (Fink et al., 2002; Jones, 1997; Wann et al., 1996; Wann et al., 2001) resulted in the selection of the following independent variables for inclusion in a regression model: the quality of the players and/ or coaches of the team; where the respondent was born; the importance of parents and/or family members being fans; the importance of tailgating/ party atmosphere; and the importance of friends being fans. A further review of past research on sport fan team identification (Fink et al., 2002; Jones, 1997; Wann et al., 1996; Wann et al., 2001) indicated that, although the above independent variables have been identified as significant predictors of team identification, their relative predictive value is uncertain. A simultaneous multiple regression analysis with all independent variables entered at the same time was, therefore, used to build a predictive model of initial team identification for sport fans. The results presented in Table 3 indicate that parents and/or family $(\beta=.125, p<.05)$, born and/or live in area $(\beta=.210, p<.001)$, friends are fans $(\beta=-.149, p<.01)$, players and/or coaches $(\beta=.411, p<.001)$, and tailgating and party atmosphere $(\beta=.123, p<.05)$ were significant predictors of team identification. All of these variables were significant positive predictors, except the friends as fans variable. Although the overall variance explained by the regression model $\left(R^{2}=.287\right)$ was low, the results support the notion that both intrinsic and extrinsic factors are significant predictors of initial sport fan team identification in a mid-level professional sport, $F(8,324)=$ 16.30, $p<.001$. 
Table 3. Summary of multiple regression analysis for variables predicting team identification

\begin{tabular}{llll}
\hline Variable & $\mathrm{B}$ & SE B & $\beta$ \\
\hline Players and/or coaches & 2.126 & .278 & $.411^{* * * *}$ \\
Native/resident & .930 & .213 & $.210^{* * *}$ \\
Family are fans & .595 & .236 & $.125^{*}$ \\
Tailgating/party atmosphere & .566 & .239 & $.123^{*}$ \\
Friends are fans & -.672 & .243 & $-.149^{* *}$ \\
Team success & -.303 & .280 & -.057 \\
Dance team & .215 & .216 & .058 \\
Closest team & .357 & .222 & .079 \\
\hline
\end{tabular}

$* p<.05, * p<<.01, * * \mathrm{p}<.001$

$N=351$

\section{Discussion}

The results of this study provide validation of the SSIS as well as insight into the relationship between team identification and the reasons for initially becoming a fan of a team. Prior research has found parental influence, talent level and personality of players, peer influence, geographic influence and success of the team as the five most prevalent reasons given by sport fans for initial identification with a team (Fink et al., 2002; Jones, 1997; Wann et al., 1996). The results of this study, however, indicate that the players and/or coaches of the team, being native to or currently living in the area, friends and family as fans, and tailgating and partying atmosphere each accounted for a portion of the variability in initial sport fan team identification. The differing results may be due to several contributing factors. For example, Wann et al. (1996) sampled college students and asked the participants to record reasons for initially becoming a fan of their favorite professional or collegiate team. The current study involved fans of a specific second-year mid-level professional sport franchise. Therefore, we would expect some level of variation in the relative importance of contributing factors for initial team identification.

The analysis of associations between reasons for becoming a fan and sport fan team identification in this study yielded some surprising and interesting results. Significant associations were found between team identification and players/coaches, family and friends, team success, tailgating/party atmosphere, and geographic influences. The positive association between the importance of tailgating and party atmosphere and team identification, which has not been included in previous research, is not unique to arena football. A tailgating and party atmosphere plays an important role in sport fan team identification for arena football as well as collegiate and professional football and other sports. Although the demographics of certain sports may not seem to naturally align with this type of social variable (i.e. tailgating is typically associated with the southern United States), these results indicate professional sport teams should do more to foster a social 
environment in the parking lot, the surrounding area, and/or the sport facility.

One of the most surprising results to the Cobras' team management was that the players' and/or coaches' variable was found to be the strongest predictor of sport fan team identification. Although the role of player talent has been identified as an important predictor of sport fan identification in previous research (Fink et al., 2002; Jones, 1997; Wann et al., 1996), it was not expected to play such an important role in this study due to the focused marketing efforts on entertainment value. The AFL has typically marketed the exciting and fast-paced elements of arena football as well as the affordability of their product while de-emphasizing the importance of individual players. Marketing strategies for the Cobras were focused on promoting the overall entertainment experience with the team's dance squad (the 'Snake Charmers') featured more prominently in promotions than players or coaches. However, the 'Snake Charmers' variable did not exhibit a positive association with team identification. Among other factors, the failure to heed the advice gained from this aspect of the study may have potentially contributed to the relocation and eventual disbandment of the Cobras' franchise.

The second strongest predictor of team identification was being a native or a resident in the area. This result was supported by prior research on geographical influences (Jones, 1997; Wann et al., 1996). The other geographic variable, closest AFL team, was not a significant predictor. We believe these results reflect the new sport and team and the local nature of fans supporting the Cobras team. For example, the Atlanta Braves and the Baltimore Orioles are the two closest Major League Baseball (MLB) franchises to North Carolina. Therefore, for native North Carolinians, these two teams dominate the state in terms of rooting interests for MLB. For local fans, in the case of the Carolina Cobras, pride in your hometown team is obviously a significant factor for initial identification with a team.

Surprisingly, the friends as fans variable was a negative predictor of initial team identification. These results contradict previous research (Fink et al., 2002; Wann et al., 1996). We believe this result to be an anomaly and further indication that a new sport and new team in a new market produces different results than studies of sport teams in established markets. In established sport markets, friendships often form or thrive around rooting interests. In the present case, these types of friendships did not have time to form in a manner significant enough to even become a positive predictor of team identification. We believe that over the life of the sport franchise, the predictive value of the friends as fans variable would shift in a more positive direction. In contrast to the friends as fans variable, the parents and family variable was a significant positive predictor of team identification. In line with past research, we expected the parents/family variable to be a powerful predictor of team identification, and this factor may be particularly relevant with a new team and new sport. A possible explanation of the incongruity between these two variables (friends versus family) may simply be the 
passage of time, as fans may be more likely to share their experiences with family before branching out to share with friends.

Team success was not a significant predictor of team identification. This result also contradicted previous research (Fink et al., 2002; Wann et al., 1996) and further points to the significance of this study. We believe this result was again related to the new sport and new team. When a sport franchise first arrives in an area, there may be a 'honeymoon period' in which fans are more curious than concerned about winning or producing a championship team. The Cobras were 3-11 in the inaugural season and 2-1 at the time of the study (Arena Football Team History, 2006). This phenomenon would likely be even more pronounced with a new sport such as arena football, and the results support that contention. However, 'honeymoon periods' end, and the Carolina Cobras' franchise experienced the harsh reality of numerous factors contributing to that demise, notably a $22-52$ overall record in five seasons of play (Arena Football Team History, 2006).

\section{Implications for Sports Marketing}

The results of this study clearly demonstrate that players' talent plays a more important role in the development of highly identified sport fans than entertainment-focused marketing. This important lesson was highlighted most notably in the case of the high-profile failure of the American Xtreme Football League (XFL), a mid-level professional sport league that sought to market towards established American football fans with an entertainment heavy yet inferior product (i.e. talent level of players and coaches). The league lasted only one season and folded due to lack of overall fan support. The results of the current study as well as the XFL example should be an enduring lesson for any burgeoning franchise or new mid-level professional sport or league.

While marketing and promotion strategies centered on entertainment value may draw fans in the short term, do these fans eventually become identified with the team and spend more money in the long run? This question has not been answered fully, but the results of the current study perhaps lend some credence to the notion that these fans do not become the noted and coveted 'diehards.' The results of the study point to the following ideal scenario for marketing a new team to potential sport fans in a new market: Promote geographical and family variables as well as the talent level and personalities of players and coaches and provide an environment in which tailgating and partying should be an option. The reward for these efforts is sport fans with high team identification who will attend more games and spend more money in the process. This information is not groundbreaking, but it further solidifies the elements of a successful sport business. However, the current study does have limitations and should not be generalized to the general sport fan population at large.

The tailgating and party atmosphere variable was added to this study based on a request by the Vice President of Marketing and proved to be a 
valuable associative and predictive variable for team identification. Although a case could be made for this variable as specific to football or the southern United States, we believe the results point to a desire by fans to enjoy themselves prior to sporting events. If an organization can foster an atmosphere in which people have more fun and spend more time at the sport facility, the potential exists not only for creating more fans but also generating more revenue. A cogent example of this phenomenon occurred at the same venue as the one originally occupied by the Carolina Cobras. Initially, the Carolina Hurricanes of the National Hockey League (NHL) banned fans from tailgating prior to the game, believing that this aspect would cause more trouble and headaches for venue and team management than the potential worth. After a backlash from fans, the decision was reversed. In their run to the Stanley Cup championship in 2006, the national media repeatedly highlighted the Hurricanes fans' tailgating as a unique aspect to professional hockey in the southern United States.

\section{Limitations and Future Research}

This study utilized convenience sampling and, although more generalizeable from a marketing point of view than sampling college students, a random sample would have provided more scientific relevance. Due in part to the non-random nature of the study, season ticket holders were the primary survey respondents and may have skewed the data. A random sample of season ticket holders, mini-package, and single game ticket purchasers would have been more effective in generalizing to mid-level professional sport populations. Second, data collection was conducted at a single game so the results are limited to the sample that attended one specific game. The results may differ based on the day or time of the game, the opponent, or the team's win-loss record.

This study offers insight into sport fan team identification relative to a previously understudied population, but several issues should be addressed in future research. Sport management scholars have worked to develop comprehensive conceptual models and measurement tools related to the motivations of sport spectators (e.g. Funk \& James, 2001; Funk et al., 2002; Trail et al., 2000; Trail et al., 2003; Trail \& James, 2001; Wann, 1995). The relationship between team identification and the reasons for initially becoming a fan of a particular team should continue to be explored, whether validating or refuting previous research, in an attempt to further understand the myriad of contextual factors surrounding any sport team or league. With continued research of new markets, researchers should be able to develop a conceptual model based on sport type and level of competition. The research highlighted several areas of particular interest for future study, namely the lack of predictive value for the entertainment-oriented variable of the Cobras' dance team and the predictive value of the tailgating and party atmosphere. Mid-level professional sport teams should not be ignored, and research on new mid-level professional sport teams in new markets provide a unique opportunity to study team identification formation. 
Over the course of the last five decades, sport has evolved toward a more entertainment-focused product, as television and electronic media have risen to prominence. The world's leading sport television broadcaster, ESPN or Entertainment and Sports Production Network, lends credence to this notion. Some of the emphasis has shifted away from that which cannot be controlled, the game, towards what can be manipulated (the entertainment). The current research highlighted one small element of this entertainment focus, the Cobras' dance team, and revealed a lack of associative or predictive value for sport fan team identification formation. This result by no means suggests that entertainment-oriented sport variables are not valuable commodities in enhancing the overall sport fan experience. However, the result does point towards the need for additional research into these entertainment variables.

The tailgating and party atmosphere surrounding sport events has not been studied extensively, as James et al. (2001) reported their research as the first to study the phenomenon. The current results point to a need for increased study. American football has risen to prominence in the United States, as there is little doubt of the sport's current position as the nation's most popular sport. Tailgating plays a major role in that success, as American football is the sport most commonly associated with the phenomenon. Research into the success of efforts by other sports to enhance the tailgating and party atmosphere will provide not only interesting comparisons across sport contexts but further identify whether this variable is more ancillary than predictive in relation to sport fan team identification formation.

Sports are and will remain an integral part of our society as a whole. Midlevel professional sport teams play an important role in contributing to the overall makeup of many communities across the world. Their initial and continued success will only serve to strengthen the economic and social infrastructure of their respective communities. Sport fans are vital to both initial and continued success of a sport franchise. By continuing to research sport fans, we will gain valuable insight that will both enhance the experience for fans and draw new and more diverse customers for sport franchises.

\section{Note}

1. The Carolina Cobras franchise relocated to Charlotte after three seasons in Raleigh (2000-2). After two seasons in Charlotte (2003-4), the franchise disbanded in 2004.

\section{References}

Arena Football Team History. (2006). Arena Fan Online. Retrieved 12 July, 2006 from http:// www.arenafan.com/history/

Branscombe, N. R., \& Wann, D. L. (1991). The positive and self concept consequences of sports team identification. Journal of Sport and Social Issues, 15, 115-127.

Fink, J. S., Trail, G. T., \& Anderson, D. F. (2002). An examination of team identification: which motives are most salient to the existence? International Sports Journal, 6(2), 195-207. 
Funk, D. C., \& James, J. D. (2001). The psychological continuum model: A conceptual framework for understanding and individuals' psychological connection to sport. Sport Management Review, 4, 119-150.

Funk, D. C., Mahony, D. F., \& Ridinger, L. L. (2002). Characterizing consumer motivation as individual difference factors: Augmenting the sport interest inventory (SII) to explain level of spectator support. Sport Marketing Quarterly, 11(1), 33-43.

Gayton, W. F., Coffin, J. L., \& Hearns, J. (1998). Further validation of the Sports Spectator Identification Scale. Perceptual and Motor Skills, 87 (3, Part 2), 1137-1138.

James, J. D., Breezeel, G.. S., \& Ross, S. (2001). A two-stage study of the reasons to begin and continue tailgating. Sport Marketing Quarterly, 10 (4), 212-222.

James, J. D., \& Ross, S. D. (2004). Comparing sport consumer motivations across multiple sports. Sport Marketing Quarterly, 13, 17-25.

Jones, I. (1997). A further examination of the factors influencing current identification with a sports team, a response to Wann et al. (1996). Perceptual and Motor Skills, 85, 257-258.

Madrigal, R. (1995). Cognitive and affective determinants of fan satisfaction with sporting event attendance. Journal of Leisure Research, 27, 205-227.

Pease, D. G., \& Zhang, J. J. (1996). Differentiation of fan psychology with respect to sociodemographic backgrounds of NBA spectators. Research Quarterly for Exercise and Sport, 67, A100.

Trail, G. T., Anderson, D. F., \& Fink, J. S. (2000). A theoretical model of sport spectator consumption behavior. International Journal of Sport Management, 1, 154-180.

Trail, G. T., Fink, J. S., \& Anderson, D. F. (2003). Sport spectator consumption behavior. Sport Marketing Quarterly, 12(1), 8-17.

Trail, G. T., \& James, J. D. (2001). The motivation scale for sport consumption: Assessment of the scale's psychometric properties. Journal of Sport Behavior, 24(1), 108-127.

Wakefield, K. L. (1995). The pervasive effects of social influence on sporting event attendance. Journal of Sport \& Social Issues, 19, 335-351.

Wann, D. L. (1995). Preliminary validation of the Sport Fan Motivation Scale. Journal of Sport \& Social Issues, $19,377-396$.

Wann, D. L. (1996). Seasonal changes in spectators' identification and involvement with and evaluations of college basketball and football teams. Psychological Record, 46 (1), 201-215.

Wann, D. L., \& Branscombe, N. R. (1993). Sports fans: Measuring degree of identification with their team. International Journal of Sport Psychology, 24, 1-17.

Wann, D. L., \& Dolan, T. J. (1994). Attributions of highly identified sports spectators. Journal of Social Psychology, 134(6), 783-794.

Wann, D.L., Ensor, C.L., \& Bilyeu, J. K. (2001). Intrinsic and extrinsic motives for originally following a sport team and team identification. Perceptual and Motor Skills, 93 (2), 451-454.

Wann, D. L., Melnick, M. J., Russell, G. W., \& Pease, D. G. (2001). Sport fans: the Psychology and Social Impact of Spectators. New York: Routledge.

Wann, D. L., Pierce, S., Padgett, B., Evans, A., Krill, K., \& Romay, A. (2003). Relations between sport team identification and optimism. Perceptual and Motor Skills, 97 (3, Part 1), 803-804.

Wann, D. L., Roberts, A., \& Tindall, J. (1999). The role of team performance, team identification, and self-esteem in sport spectators' game preferences. Perceptual and Motor Skills, 89, 945-950.

Wann, D. L., \& Schrader, M. P. (1997). Team identification and the enjoyment of watching a sporting event. Perceptual and Motor Skills, 84, 954.

Wann, D. L., Tucker, K. B., \& Schrader, M. P. (1996). An exploratory examination of the factors influencing the origination, continuation, and cessation of identification with sports teams. Perceptual and Motor Skills, 82, 995-1001. 